\title{
Isolation and Characterization of Selenate Resistant Mutants of Acremonium chrysogenum
}

\author{
Airton Vialta $^{1^{*}}$, Cleide F. Catani ${ }^{2}$, Renato B. Junior ${ }^{1}$ and João L. Azevedo ${ }^{3}$ \\ ${ }^{1}$ Instituto de Tecnologia de Alimentos. Avenida Brasil, 2880. CEP.13073-001.Campinas-SP, Brasil; ${ }^{2}$ Universidade \\ Estadual de Campinas. Departamento de Microbiologia e Imunologia. CEP 13083-970. Campinas- SP, Brasil; \\ ${ }^{3}$ ESALQ - USP. Departamento de Genética. CEP 13418-900. Piracicaba - SP, Brasil.
}

\begin{abstract}
Mutants unable to convert exogenous sulfate to sulfite were isolated using the toxic analogue selenate. Three of twenty-eight isolated mutants were chromate sensitive. They showed a possible lesion in the gene that codes the ATP sulfurylase. The others were chromate resistant, and probably had a lesion in one or both of the genes that code the sulfate permease. Methionine increased the resistance levels to selenate. In addition, the frequency of spontaneous mutants obtained in a medium containing methionine was higher (between $2.4 \times 10^{-6}$ and $18.0 \times 10^{-6}$ ) than that obtained using a medium without any intentional source of sulfur (between $0.7 \times 10^{-6}$ and $5.0 \times 10^{-6}$ ). The original strain, as well as the mutants, were able to grow in a sulfur-free liquid medium even after 4 consecutive inoculation procedures. These results indicated the existence of sulfur traces in the medium and/or an efficient intracellular storage system. There was no significant difference between cephalosporin C production in mutants and the original strain.
\end{abstract}

Key words: Selenate resistant mutant, Acremonium chrysogenum, cephalosporin C

\section{INTRODUCTION}

Microbiological and biochemical analyses of Acremonium chrysogenum mutants for sulfur metabolism showed that wild strains of this species probably have three regulation mechanisms, two of which are related to the conversion of sulfate to cysteine, where the control is carried out by methionine. The third, $O^{-}$acetyl serine, induces the enzymes that convert sulfate to cysteine (Queener et al. 1984). Methionine also plays a fundamental role in the biosynthetic pathway of cephalosporin C. It is the major donor of sulfur atoms, in addition to the stimulation of antibiotic synthesis (Nüesch et al. 1973; Drew \& Demain, 1975). Using Aspergillus nidulans, it is possible to isolate mutants that cannot use toxic analogues, such as selenate and chromate, to convert exogenous sulfate to sulfite (Arst, 1968). The most common selenate resistant mutations in A. nidulans result in either loss of sulfate permease, produced by the $s B$ gene, or of ATP sulfurilase, produced by the $s C$ gene. These two mutations can be easily distinguished. $s B^{-}$mutants are both chromate and selenate resistant, whereas the $s C^{-}$mutants are selenate resistant and chromate sensitive (Arst, 1968). $s C^{-}$mutants of A. nidulans, A. niger and $A$. oryzae were transformed by complementation, using the $s C$ gene isolated from A. nidulans (Buxton et al., 1989; Yamada et al., 1997). When the transformants were plated on minimal medium containing sulfate as the sole source of sulfur, they showed normal growth.

This system has been studied for yeasts in the last few years. Smith et al. (1995) isolated a mutant of Sacchromyces cerevisiae, deficient in its capacity to transport sulfate into the cells, obtained a clone which complemented this mutation and identified a cDNA fragment that encoded a high affinity sulfate transporter, responsible for the transfer of sulfate across the plasma membrane from the external medium. Other genes related to sulfate transport were isolated (Cherest et al., 1997) and a structural realtionship between ATP sulfurylase and sulfate membrane transporters was proposed (Logan et al., 1996). Treichler et al. (1978)

\footnotetext{
* Author for correspondence
} 
carried out studies using strain $8650-\mathrm{S}^{-}$of $A$. chrysogenum, which was not able to absorb inorganic sulfate, but showed growth in other sulfur sources such as sulfite, thiosulfate and sulfide. Despite its incapacity to metabolize sulfate, strain 8650-S exhibited a residual growth in media without sulfate, while wild strains showed a vigorous residual growth. The existance of residual growth in selective medium may be a problem during the characterization of mutants or during the isolation of transformant colonies. This growth was thought to be caused by sulfur compound traces that cannot be eliminated from chemically defined culture media (Treichler et al. 1978). These studies were usually carried out in liquid media, because agar contains significant quantities of covalently bound organic sulfur in a form that may support the growth of the strains (Queener et al. 1984).

The objectives of this study were to isolate selenate resistant mutants of the $\mathrm{C}-10$ strain of A. chrysogenum, to check their level of resistance to selenate as well as their sensitivity to chromate, and to transform $s C^{-}$mutants by comple-mentation, using a plasmid with the $s C$ gene and genes that could cause an improvement in cephalosporin $\mathrm{C}$ production. Growth and titer levels of cephalosporin $\mathrm{C}$ of resistant mutants were determined and compared with those of the original strain.

\section{MATERIALS AND METHODS}

Microorganisms and maintenance: Strain C10 of Acremonium chrysogenum (ATCC 48272) was used. Stock cultures were maintained on $\mathrm{CM}$ slants at $5^{\circ} \mathrm{C}$.

Media used: Minimum medium (MM) contained (g.L $\left.{ }^{-1}\right)$ : sucrose, 20; $\mathrm{NaNO}_{3}, 3.0$; $\mathrm{K}_{2} \mathrm{HPO}_{4}, \quad 0.5 ; \quad \mathrm{KH}_{2} \mathrm{PO}_{4}, \quad 0.5 ; \quad \mathrm{KCl}, \quad 0.5 ;$ $\mathrm{MgSO}_{4} 7 \mathrm{H}_{2} \mathrm{O}, \quad 0.5 ; \quad \mathrm{FeSO}_{4} 7 \mathrm{H}_{2} \mathrm{O}, 0.01, \quad \mathrm{pH}$ 7.2.Solid MM was prepared with 15 g.L $\mathrm{L}^{-1}$ of agar (Difco). Complete medium (CM) contained MM plus (g. $\left.\mathrm{L}^{-1}\right)$ : yeast extract, 4.0 and bactopeptone (Difco), 4.0. Minimum medium without sulfur source (MMS) was prepared same as $\mathrm{MM}$, but replacing $\mathrm{MgSO}_{4} 7 \mathrm{H}_{2} \mathrm{O}$ and $\mathrm{FeSO}_{4} \cdot 7 \mathrm{H}_{2} \mathrm{O}$ with $\mathrm{MgCl}_{2} \cdot 6 \mathrm{H}_{2} \mathrm{O}$ and $\mathrm{FeCl}_{3} 6 \mathrm{H}_{2} \mathrm{O}$. Seed medium (SM): SM contained $\left(\mathrm{g} . \mathrm{L}^{-1}\right)$ : soluble starch, 40; corn steep liquor, 30; soybean meal, 10; soybean oil, 20; $\mathrm{CaCO}_{3}, 3.0$; $\left(\mathrm{NH}_{4}\right)_{2} \mathrm{SO}_{4}, 1.0, \mathrm{pH}$ 7.0. Fermentation medium (FM) contained (g.L $\left.{ }^{-1}\right)$ : sucrose, 36; glucose, 27; yeast extract (Difco), 20; soybean oil, 24; $\mathrm{CaSO}_{4}, 7.5 ; \mathrm{CaCO}_{3}, 10 ;\left(\mathrm{NH}_{4}\right)_{2} \mathrm{SO}_{4}, 8.0$; D,Lmethionine, 3.0, $\mathrm{pH} 6.4$.

All the media were autoclaved at $121^{\circ} \mathrm{C}$ for 15 min. Incubations were carried out at $25^{\circ} \mathrm{C}(250$ rpm) for 2 and 6 days for seed and fermentation (including mycelial growth in MM and $\mathrm{MMS}^{-}$), respectively.

In order to isolate and characterize resistant mutants, mycelia of 7 day old cultures of $A$. chrysogenum C-10 in MM were suspended in 6 $\mathrm{ml}$ of saline. Suspensions were transferred to test tubes containing glass beads and homogenized for $1 \mathrm{~min}$. in a vortex. These suspensions were mixed with solid $\mathrm{MMS}^{-}$at $45^{\circ} \mathrm{C}$ containing 10 mg. $\mathrm{L}^{-1}$ of D,L-methionine and sodium selenate (0 to $102.4 \mathrm{mM}$ ) and transferred to petri dishes. After incubation, colonies with vigorous growth were isolated, and the mutation frequency estimated. Mutation frequencies were also obtained on $\mathrm{MMS}^{-}$without D,L-methionine. In this case, selenate concentrations varied between 0 and $0.8 \mathrm{mM}$. The resistant mutants were characterized on $\mathrm{MMS}^{-}$containing $2 \mathrm{mg} . \mathrm{L}^{-}$ 1 of D,L-methionine and selenate at the following concentrations: $0,0.1,0.2,0.4,0.8$ and $1.6 \mathrm{mM}$. In order to determine resistance or sensitivity to chromate, the suspensions were mixed with $\mathrm{MMS}^{-}$containing $0.1 \mathrm{mM}$ of sodium chromate.

Chromate resistant mutants were characterized pouring suspensions prepared as described above into $\mathrm{MMS}^{-}$containing $10-\mathrm{mg} . \mathrm{L}^{-1}$ of $\mathrm{D}, \mathrm{L}-$ methionine and chromate at the following concentrations: $0.005,0.01,0.02,0.04,0.08$ and $0.16 \mathrm{mM}$.

Suspensions prepared as described above were centrifuged, washed 3 times with saline, diluted and inoculated in to $250 \mathrm{ml}$ erlenmeyers containing $25 \mathrm{ml}$ of liquid $\mathrm{MM}$ in order to achieve a final concentration of $10^{6}$ c.f.u. $/ \mathrm{ml}$. After incubation, the cultures were filtered and the dry weight was determined. One $\mathrm{ml}$ of 
cultures grown in $\mathrm{MMS}^{-}$was used to inoculate the erlenmeyers containing $\mathrm{MM}$ and $\mathrm{MMS}^{-}$. After incubation, $1 \mathrm{ml}$ of cultures growing in both media was used to inoculate a new set of MM and MMS- This procedure was repeated 4 times. This experiment was performed in duplicate.

Cephalosporin $\mathrm{C}$ production was determined by tranferring $2.5 \mathrm{ml}$ of the above mentioned suspension to a $500 \mathrm{ml}$ erlenmeyer that contained $50 \mathrm{ml}$ of seed medium. After incubation, $1.6 \mathrm{ml}$ were used to inoculate the fermentation flasks. Fermentation was carried out in 500-ml erlenmeyers containing $40 \mathrm{ml}$ of FM. Cephalosporin C was determined by HPLC after filtration through a $0.20 \mu \mathrm{m}$ filter (Millipore). Analysis were carried out in a Varian (9010 and 9050) chromatograph with a Lichrospher RP-18 column (Merck) using a 254 $\mathrm{nm}$ detector. The mobile phase was $0.03 \%$ $\mathrm{KH}_{2} \mathrm{PO}_{4} \quad(\mathrm{w} / \mathrm{v})$. The Mann-Withney test (Roscoe, 1975) was used for the statistical analysis.

\section{RESULTS}

It was observed that concentrations higher than $12.8 \mathrm{mM}$ completely inhibited the growth of sensitive colonies (Table 1). However, when $\mathrm{MMS}^{-}$without D,L-methionine was used, a selenate concentration of only $0.05 \mathrm{mM}$ (256 times lower) was sufficient to cause total inhibition (Table 2). These results showed clearly that the presence of $\mathrm{D}, \mathrm{L}-$ methionine in $\mathrm{MMS}^{-}$increased the resistence of the C-10 strain to selenate.

Colonies showing vigorous growth were observed in all plates containing selenate. These colonies were classified as possible mutants and their frequencies estimated between $2.4 \times 10^{-6}$ and $18.0 \times 10^{-6}$ for experiments carried out with $\mathrm{MMS}^{-}$contaning $\mathrm{D}, \mathrm{L}-$ methionine, and between $0.7 \times 10^{-6}$ and $5.0 \times 10^{-6}$ for MMS.

Table 1: Growth and frequency of possible spontaneous mutants in $\mathrm{MMS}^{-}$containing different concentrations of selenate and $10 \mathrm{mg} . \mathrm{L}^{-1}$ of $\mathrm{D}, \mathrm{L}-$ methionine $\left(1.33 \times 10^{6}\right.$ c.f.u./plate $)$

\begin{tabular}{cccc}
\hline $\begin{array}{c}\text { Selenate } \\
(\mathrm{mM})\end{array}$ & Growth $^{\text {a }}$ & $\begin{array}{c}\text { Number of } \\
\text { mutants per } \\
\text { plate }\end{array}$ & $\begin{array}{c}\text { Frequency } \\
\text { of mutants } \\
\left(10^{-6}\right)\end{array}$ \\
\hline 0 & +++ & NE & \\
0.4 & ++ & 4.6 & 3.5 \\
0.8 & + & 17.5 & 13.2 \\
1.6 & + & 17.0 & 12.8 \\
3.2 & + & 15.5 & 11.6 \\
6.4 & + & 24.0 & 18.0 \\
12.8 & - & 18.0 & 13.5 \\
25.6 & - & 16.5 & 12.4 \\
51.2 & - & 14.0 & 10.5 \\
102.4 & - & 3.0 & 2.4 \\
\hline NE $=$ not estimated, (a) $+++=$ vigorous growth, \\
$++=$ moderate growth, += poor growth, \\
- only mutants grew
\end{tabular}

Table 2: Growth and frequency of spontaneous mutants on $\mathrm{MMS}^{-}$containing different concentrations of selenate $\left(1.4 \times 10^{6}\right.$ c.f.u./plate).

\begin{tabular}{cccc}
\hline $\begin{array}{c}\text { Selenate } \\
(\mathrm{mM})\end{array}$ & Growth $^{\mathrm{a}}$ & $\begin{array}{c}\text { Number of } \\
\text { mutants per } \\
\text { plate }\end{array}$ & $\begin{array}{c}\text { Frequency } \\
\text { of mutants } \\
(\mathrm{x} \mathrm{10})\end{array}$ \\
\hline 0 & +++ & $\mathrm{NE}$ & \\
0.05 & - & $\mathrm{NE}$ & \\
0.10 & - & 7 & 5.0 \\
0.15 & - & 5 & 3.6 \\
0.20 & - & 5 & 3.6 \\
0.30 & - & 1 & 0.7 \\
0.40 & - & 3 & 2.1 \\
0.80 & - & 3 & 2.1 \\
\hline NE $=$ & not estimated, (a) +++ & $=$ & vigorous \\
growth, & $-\quad=$ only mutants grew
\end{tabular}

Table 3: Dry weight (in mg) of the C-10 strain and mutants growing in liquid media (MM and MMS') with agitation, in four serial replications.

\begin{tabular}{|c|c|c|c|c|c|c|c|c|}
\hline \multirow[t]{3}{*}{ Step } & \multicolumn{8}{|c|}{ Mutants } \\
\hline & \multicolumn{2}{|c|}{ SC1 } & \multicolumn{2}{|c|}{$\mathrm{SC} 2$} & \multicolumn{2}{|c|}{ SB1 } & \multicolumn{2}{|c|}{ C-10 } \\
\hline & MM & $\mathrm{MMS}^{-}$ & $\mathrm{MM}$ & $\mathrm{MMS}^{-}$ & $\mathrm{MM}$ & $\mathrm{MMS}^{-}$ & $\mathrm{MM}$ & $\mathrm{MMS}^{-}$ \\
\hline 1 & $118^{*} \pm 6$ & $99 \pm 13$ & $102 \pm 15$ & $98 \pm 11$ & $113 \pm 8$ & $100 \pm 16$ & $67 \pm 17$ & $113 \pm 9$ \\
\hline 2 & $153 \pm 14$ & $11 \pm 3$ & $88 \pm 16$ & $9 \pm 1$ & $46 \pm 8$ & $12 \pm 2$ & $135 \pm 14$ & $12 \pm 2$ \\
\hline 3 & $145 \pm 9$ & $9 \pm 3$ & $115 \pm 5$ & $14 \pm 4$ & $127 \pm 12$ & $15 \pm 5$ & $140 \pm 18$ & $17 \pm 5$ \\
\hline 4 & $165 \pm 23$ & $7 \pm 4$ & $126 \pm 10$ & $6 \pm 3$ & $125 \pm 7$ & $2 \pm 1$ & $141 \pm 11$ & $7 \pm 2$ \\
\hline
\end{tabular}

* average of 2 measures. 
Thirty two possible mutants were isolated and purified from $\mathrm{MMS}^{-}$and $\mathrm{MMS}^{-}$with $\mathrm{D}^{-} \mathrm{L}^{-}$ methionine, both containing selenate. All isolates had resistance to selenate confirmed in MMS containing $2 \mathrm{mg} \cdot \mathrm{L}^{-1}$ of $\mathrm{D}, \mathrm{L}^{-}$methionine.

A lower concentration of this aminoacid was used in order to utilize lower concentrations of selenate.

As previously commented, there is an inverse relationship between methionine concentration and sensitivity to selenate. In $\mathrm{MMS}^{-}$ supplemented with $2 \mathrm{mg} . \mathrm{L}^{-1}$ of D,L-methionine, strain C-10 was completely inhibited by $0.1 \mathrm{mM}$ of selenate. All mutants tested were able to grow in the highest concentration $(1.6 \mathrm{mM})$.

Strain C-10 and all selenate resistant mutants were poured into MMS $^{-}$containing $10 \mathrm{mg} \cdot \mathrm{L}^{-1}$ of D.L-methionine and different concentrations of chromate, in order to detect their sensitivity to this ion. Only 3 selenate resistant mutants were chromate sensitive, inhibited by $0.04 \mathrm{mM}$ of chromate (data not shown).

Strain C-10 and mutants SC1, SC2 and SB1, were tested in liquid MM and MMS-. They were able to grow without any intentional source of sulfur, even after four serial inoculations (Table 3). Although mutants had their sulfur metabolism pathways blocked, they showed growth similar to that of the strain C-10. The cephalosporin $\mathrm{C}$ titer of the 28 mutants tested were determined (Figure 1). A statistical analysis of the data showed that there was no significant difference in cephalosporin $\mathrm{C}$ production between the mutants and the strain C-10 (Table 4).

Table 4: Statistical analysis of cephalosporin C production showed by $\mathrm{C}-10$ strain and mutants using Mann - Withney nonparametrical test

\begin{tabular}{lcccc}
$\begin{array}{l}\mathrm{C}-10 \\
\text { strain }\end{array}$ & Mutants & Average & $\begin{array}{c}\text { Standard } \\
\text { Deviation }\end{array}$ & $\mathrm{Z}$ \\
\hline $\mathrm{n}=28$ & $\mathrm{n}=28$ & $\mu \mathrm{U}=392$ & $\delta=60,99$ & $0,631^{*}$ \\
$\mathrm{R}$ & $=\mathrm{R}=759,5$ & & & \\
836,5 & & & & \\
$\mathrm{U}$ & $=\mathrm{U}=430,5$ & & & \\
353,5 & & & &
\end{tabular}

*Samples can be considered as coming from the same population $(\mathrm{P}>0,95)$.

\section{DISCUSSION}

It was observed that concentrations higher than $12.8 \mathrm{mM}$ of selenate were necessary to inhibit the growth of sensitive colonies in media containing $10 \mathrm{mg} . \mathrm{L}^{-1}$ of D,L-methionine. However, concentrations of $0.05 \mathrm{mM}, 256$ times lower, were sufficient to inhibit growth in media without D,L-methionine. These results showed clearly that D,L-methionine increased the resistence of strain C-10 to selenate. Similar results were observed by Queener et al. (1984), who obtained a complete selenate toxicity revertion of $\mathrm{M}-8650$ by adding $100 \mathrm{mg} . \mathrm{L}^{-1}$ of $\mathrm{D}, \mathrm{L}-$ methionine to the medium. The level of tolerance to selenate shown by strain C-10 in $\mathrm{MMS}^{-}$containing D,Lmethionine, was higher than that found with Aspergillus sp. (Arst, 1968; Buxton et al., 1989), whose inhibition levels were about $0.05 \mathrm{mM}$. 

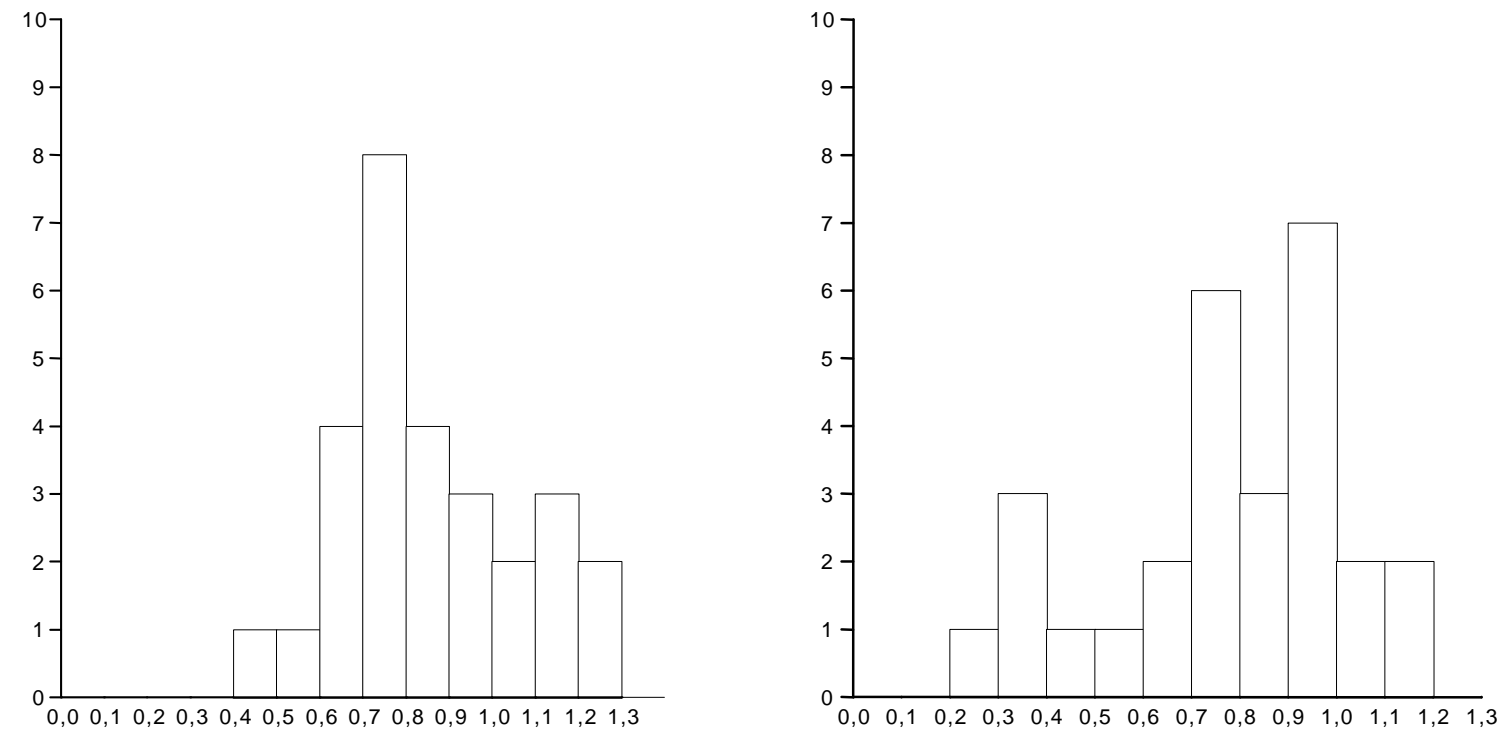

Cephalosporin C concentration (g.L $\left.\mathrm{L}^{-1}\right)$

Figure 1: Cephalosporin $\mathrm{C}$ production shown by strain C-10 and mutants.

The frequencies observed of possible mutants were lower in media without D,L-methionine. As $\mathrm{MMS}^{-}$did not contain any intentional source of sulfur, the cells were required to make use of their own reserves or of traces of this element that could be present in the medium. This could also explain the small number of mutants obtained with $\mathrm{MMS}^{-}$. An inverse relationship was observed between

methionine concentration and sensitivity to selenate. Similar results were obtained by Queener et al. (1984) working with strain M8650 of A.chrysogenum. Strain C-10 showed levels of tolerance to selenate higher than those found in Aspergillus sp.(Arst, 1968; Buxton et al., 1989).

Only three selenate resistant mutants were chromate sensitive, which therefore showed lesions in the $s C$ gene, which encodes sulfate adenyltransferase. The chromate resistant mutants had lost their sulfate permease and sulfate adenyltransferase activities. This could be due to lesions in the $s B$ genes, or in a combination of $s B$ and $s C$, as observed with $A$. nidulans (Arst, 1968) and A. niger (Buxton et al., 1989).

As previouly mentioned, strain C-10 and mutants SC1, SC2 and SB1 were able to grow without any intentional source of sulfur. These results pointed out the existence of sulfur traces in the medium and/or an efficient intracellular storage system for compounds containing this element. The mutants carrying the $s B^{-}$gene were unable to take up extracellular sulfate, and mutants carrying the $s C^{-}$gene did not metabolize it. Therefore, the cells probably used a reduced sulfur compound, like sulfite or thiosulfate, or an organic molecule that contained sulfur. Due to this characteristic, it was impossible to carry out the transformation using the $s C$ system.

There was no significant difference in the cephalosporin $\mathrm{C}$ production between the mutants and strain $\mathrm{C}-10$. These results could be explained by the presence of $\mathrm{D}, \mathrm{L}-$ methionine in the fermentation medium. As discussed above, this aminoacid can be easily metabolized by mutants unable to absorb sulfate ions. Seemingly, this mutation does not affect either the growth or cephalosporin $\mathrm{C}$ production by the microorganism. Another possibility could be the utilization of intracellular stores.

Thus, the present study showed the successful isolation of the mutants resistant to selenate using strain C-10 of A. chrysogenum, and, dispite their incapacity of metabolize sulfate, 
they exhibited a residual growth in media without sulfate.

\section{ACKNOWLEDGMENTS}

The authors would like to thank Dr. Robert T. Rowlands from the Fermentation Services Division - PANLABS for providing strain C-10 and Conselho Nacional de Desenvolvimento Científico e Tecnológico (CNPq) for the RHAE fellowships.

\section{RESUMO}

Mutantes incapazes de converter o sulfato extracelular em sulfito foram isolados utilizando o análogo tóxico selenato. De 28 mutantes isolados, apenas 3 foram sensíveis ao cromato, provavelmente apresentando lesão no gene que codifica a ATP sulfurilase. Os demais foram resistentes ao cromato e devem conter lesão no gene $s B$ ou também no gene $s C$. A metionina elevou os níveis de resistência ao selenato e a freqüência de mutantes espontâneos obtida em meio contendo este aminoácido foi maior (entre $2,42 \times 10^{-6}$ e $18,04 \times 10^{-6}$ ) do que a obtida no meio sem a adição de qualquer fonte intencional de enxofre (entre $0,71 \times 10^{-6}$ e $5,0 \times 10^{-6}$ ). A linhagem original e os mutantes foram capazes de crescer, mesmo depois de quatro etapas de inóculo, fato que pode ser explicado pela existência de traços do referido elemento no meio e/ou a presença de um sistema eficiente de estocagem intracelular. A produção de cefalosporina $\mathrm{C}$ foi estudada e a análise dos dados revelou que não houve diferença significativa entre os níveis produzidos pelos mutantes e os produzidos pela linhagem original.

\section{REFERENCES}

Arst, H.N. (1968), Genetic analysis of the first steps of sulphate metabolism in Aspergillus nidulans. Nature (London), 219, 268-270.

Buxton, F.P.; Gwynne, D.I \& Davies, R.W. (1989), Cloning of a new bidirectionally selectable marker for Aspergillus strains. Gene, 84, 329-334.

Cherest, H.; Daidian, J.C.; Thomas, D.; Benes, V.; Ansorge, W. \& Surdin-Kerjan, Y.
(1997), Molecular characterization of two high affinity sulfate transporters in Saccharomyces cerevisiae. Genetics, 145, 627-635.

Drew, S.W. \& Demain, A.L. (1975), Production of cephalosporin $\mathrm{C}$ by single and double sulphur auxotrophic mutants of Cephalosporium acremonium. Antimicrob. Agents Chemoth., 8, 5-10.

Logan, H.M.; Cathala, N.; Grignon, C. \& Davidian, J. C. (1996), Cloning of a cDNA encoded by a member of the Arabidopsis thaliana ATP sulfurylase multigene family: Expression studies in yeast and in relation to plant sulfur nutrition. J. Biol. Chem., 271, 12227-12233.

Nüesch, J.; Treichler, H.J. \& Liersch, M. (1973), The biosynthesis of cephalosporin C. In Genetic of Industrial Microorganisms, eds. Z. Vanek, Z. Hostalek \& J. Cudlin, Elsevier Publishing Co., Amsterdam, pp. 309-334.

Queener, S.W.; Wilkerson, S.; Tunin, D.R.; Mcdermott, J.R.; Chapman, J.L.; Nash, C.; Platt, C \& Westpheling, J. (1984), Cephalosporin $\mathrm{C}$ fermentation: biochemical and regulatory aspects of sulphur metabolism. In - Biotechnology of Industrial Antibiotics, eds. E.J.Vandamme, vol. 22, Marcel Dekker Inc., N.Y., pp.141-170.

Roscoe, J.T. (1975), Fundamental Research Statistics for Behavioral Sciences, 2nd ed., Holt, Rinehart and Winston Inc., New York.

Smith, F.W.; Hawkesford, M.J.; Prosser, I.M. \& Clarkson, D. T. (1995), Isolation of cDNA from Saccharomyces cerevisiae that encodes a high affinity sulphate transporter at the plasma membrane. Mol. Gen. Genetics, 247, 709-715.

Treichler, H.J.; Liersch, M. \& Nüesch, J. (1978), Genetic and biochemestry of caphalosporin biosynthesis. In - Antibiotics and Other Secondary Metabolities, eds. Hütter, R. et al., FEMS Symposium 5., Academic Press, London, pp.177-199.

Yamada, O.; Lee, B.R. \& Gomi, K. (1997), Transformation system for Aspergillus oryzae with double auxotrophic mutations, nia D and $s C$. Bioscience Biotechnol. Biochem., 61, 1367-1369. 